\title{
Ion Channels and Drug Transporters as Targets for Anthelmintics
}

\author{
Robert M. Greenberg
}

Published online: 16 September 2014

(C) Springer International Publishing AG 2014

\begin{abstract}
Infections with parasitic helminthes, such as schistosomes and soil-transmitted nematodes, are hugely prevalent and are responsible for a major portion of the global health and economic burdens associated with neglected tropical diseases. In addition, many of these parasites infect livestock and plants used in agriculture, resulting in further impoverishment. Treatment and control of these pathogens relies on anthelmintic drugs, which are few in number, and against which drug resistance can rapidly develop. The neuromuscular system of the parasite, and in particular, the ion channels and associated receptors underlying excitation and signaling, have proven to be outstanding targets for anthelmintics. This review surveys the different ion channels found in helminths, focusing on their unique characteristics and pharmacological sensitivities. It also briefly reviews the literature on helminth multidrug efflux that may modulate parasite susceptibility to anthelmintics and may prove useful targets for new or repurposed agents that can enhance parasite drug susceptibility and perhaps overcome drug resistance.
\end{abstract}

Keywords Ion channels · Drug transporters · Helminths · Anthelmintics $\cdot$ Neglected tropical diseases $\cdot$ Schistosomiasis

\section{Introduction}

Parasitic helminths, or worms, are mainly represented by members of two phyla, the nematodes, or roundworms, and the platyhelminths, or flatworms. Parasitic nematodes include the soil-transmitted worms (e.g., ascarids, hookworms) and

R. M. Greenberg $(\square)$

Department of Pathobiology, School of Veterinary Medicine,

University of Pennsylvania, 3800 Spruce Street, Philadelphia,

PA 19104, USA

e-mail: rgree@vet.upenn.edu the filarial worms that cause diseases such as elephantiasis (lymphatic filariasis) and river blindness (onchocerciasis). Parasitic platyhelminths include the flukes (trematodes), such as schistosomes, and the tapeworms (cestodes). Helminths infect a huge proportion of the world's human population, with over 1 billion people in the developing world estimated to be infected with one or more species of worms [1-3]. Helminth infections represent a major portion of the neglected tropical diseases, and have devastating - although often underestimated - effects on the health and development of individuals and societies [4]. The causative agents and the prevalence of the most significant human infections are listed in Table 1. Parasitic helminths also infect livestock and plants (as well as companion animals), resulting in significant economic losses and production shortfalls [5, 6].

Three primary approaches for limiting and controlling these pathogens are: improved sanitation and hygiene; vaccination; and treatment with anthelmintic compounds. Educational interventions and infrastructural improvements have been shown to be highly effective at preventing helminth infection and reducing transmission [7], as well as having long-lasting benefits for general public health. However, implementation requires a substantial investment of resources and levels of management and coordination that are often not feasible in the developing world. Effective preventative and therapeutic vaccines are obviously highly desirable, but despite strong research efforts and the identification of promising candidate antigens [8, 9], there are currently no vaccines approved for use against helminth infections. Thus, both treatment and control of helminth infections depend almost entirely on a relatively small set of anthelmintic drugs. Although effective, chemotherapy as the sole line of defense is ultimately unsustainable, as reinfection, the development of drug resistance, and inconsistencies in maintenance of ongoing treatment and monitoring can hinder long-term efficacy [10]. 
Table 1 Major Helminth Infections of Humans (adapted from [1])

\begin{tabular}{lll}
\hline Agents & Disease & Prevalence \\
\hline Nematodes: soil-transmitted & & \\
Ascaris lumbricoides (roundworm) & Ascariasis & 800 million \\
Trichuris trichuria (whipworm) & Trichuriasis & 600 million \\
Necator americanus, Ancylostoma duodenale & Hookworm & 575 million \\
Strongyloides stercoralis (threadworm) & Strongyloidiasis & $30-100$ million \\
Nematodes: filarial & & 120 million \\
Wucheria bancrofti, Brugia malayi & Lymphatic filariasis & 37 million \\
Onchocerca volvulus & River blindness (onchocerciasis) & 13 million \\
Loa loa & Loiasis & 10,000 \\
Dracunculus medinensis & Dracunculiasis (guinea worm) & \\
Platyhelminths: flukes (trematodes) & & $200-300$ million \\
Schistosomes (blood flukes) & Schistosomiasis & \\
$\quad$ Schistosoma mansoni, S. haematobium & & $>400,000$ \\
$\quad$ S. japonicum, S. mekongi, S. intercalatum & & $>40$ million \\
Food-borne trematodes & Food-borne trematodiases & \\
$\quad$ Clonorchis sinensis (liver fluke) & & \\
Opsthorchis viverinni (liver fluke) & & \\
Fasciola hepatica (liver fluke) & & \\
Paragonimus spp. (lung flukes) & & \\
Fasciolopsis buski (intestinal fluke) & & \\
Platyhelminths: tapeworms (cestodes) & & \\
Taenia solium (pork tapeworm) & & \\
\hline
\end{tabular}

Platyhelminths and nematodes are multicellular animals with relatively well-developed neuromuscular systems that constitute a large proportion of the organisms' cells and gene activity, and are essential for parasite survival, development, and reproduction [11-13]. Indeed, within their definitive hosts (and also at other stages) worms often exhibit (and indeed require) exquisite control of motility, navigation, feeding, and reproductive behaviors, all dependent upon a highly-regulated, fully-functional neuromuscular system. Interference with any of these activities has the potential to disrupt a parasite's life cycle, either by killing the worm (directly, or by compromising its ability to feed or fend off host defenses), or by rendering it incapable of reproducing. It is not surprising therefore that the neuromuscular system of these organisms has been a prime target of some of the most effective anthelmintic agents available.

Underlying neuromuscular function are networks of ion channels, ligand receptors (many of which are also ion channels), neurotransmitters, peptides, transporters, and intracellular signaling pathways, all of which must be coordinated and regulated, and all of which must be integrated with the normal metabolic functioning required to maintain cell viability. Ion channels, proteins which underlie electrical excitability in cells, have been particularly useful as targets for anthelmintics. Indeed, most of the antinematodal drugs in use today target ion channels [14•]; similarly, praziquantel, the drug of choice against parasitic platyhelminths such as schistosomes and many cestodes, also appears to act on parasite ion channels (see below) $[15,16 \bullet]$.

Interestingly, ion channels are highly-conserved, ancient proteins [17-19], with representatives in both parasites and their hosts. However, many of these channel families are highly diverse, often with invertebrate-specific members. Furthermore, even extremely well-conserved proteins such as tubulin can be selectively targeted; the widely-used benzimidazole anthelmintics (e.g., albendazole, fenbendazole) inhibit microtubule polymerization by targeting tubulin [20]. Subtle variations in subtypes or structural changes (sometimes a single amino acid change) are sufficient to provide selectivity against the parasite protein.

In 2011, Wolstenholme comprehensively surveyed the literature on nematode ion channels and other neuromuscular receptors as targets of anthelmintics [14•]. Since publication of that review, several exciting new findings have appeared, including publication of new helminth genomes. Here, I revisit the drugs and their targets covered in that 2011 review, incorporating platyhelminths as well as nematodes, and include updates on some exciting recent findings. I also briefly discuss the possible role of parasite drug transporters in modulating susceptibility to anthelmintics, including evidence implicating them in drug resistance and their potential as targets for new or repurposed drugs that either potentiate 
current anthelmintics, or that act on their own to disrupt the normal physiological functions of these proteins.

\section{Ion Channels}

Ion channels are pore-forming membrane proteins and protein complexes that underlie electrical excitability and fast neurotransmission, as well as other rapidly-occurring biological functions in cells. They form a gated pathway for charged ions to flow passively across the normally impermeable lipophilic cell membrane, down the electrochemical gradient that is maintained through active (ATP-dependent) transport. As Hille has pointed out [21], the relationship of ion channels to electrical signaling is comparable with that of enzymes to metabolism. Ion channels are involved in a huge array of cellular functions, and channelopathies caused by channel mutations constitute a substantial disease burden [22]. Different ion channels have a range of selectivity, from relatively non-selective (e.g., non-selective cation channels) to highly selective for a particular ion. Activation, or gating, of ion channels can be by changes in voltage, ligand binding (extracellular or intracellular), or mechanical force. These categories are not rigid, however, as some channels can be gated by multiple types of stimuli, and channel activity can also be modulated by intracellular signals. Importantly, ion channels exhibit a rich pharmacology, and are targets of a wide variety of both naturally-occurring toxins and synthetic compounds [23], including many anthelmintic drugs (Table 2).

\section{Nicotinic Acetylcholine Receptors}

Nicotinic acetylcholine receptors (nAchRs) are members of the Cys-loop ligand-gated ion channel family that underlies rapid ionotropic neurotransmission. Like other Cys-loop channels, nAchRs contain five similar subunits (at least two $\alpha$ subunits and no more than three non- $\alpha$ subunits) in a homoor hetero-pentameric structure that surrounds a central pore. There are two extracellular ligand binding sites per receptor, and $\alpha$ subunits are required to form these sites, though non- $\alpha$ subunits can also contribute to the agonist binding site [24].

Many nAchRs localize to the neuromuscular junction, and are critical to neuromuscular signaling. Binding of extracellular acetylcholine opens the channel, allowing the flow of ions down the electrochemical gradient. nAchRs are typically cation selective and mediate excitatory responses by depolarizing the cell, although invertebrates also express anion-selective acetylcholine-gated channels that may play a role in fast inhibitory responses [25, 26•]. As with other ligand-gated channels, acetylcholine also activates a separate class of metabotropic receptors that are not ion channels, and instead act through G-protein-coupled signaling pathways.

Exposure of most organisms, including nematodes [27, 28] and some free-living flatworms [29], to cholinergic agonists causes spastic paralysis due to prolonged excitation at the neuromuscular junction. In contrast, schistosomes and other trematodes and cestodes exposed to these agents exhibit flaccid paralysis, indicative of an inhibitory response [30, 31]. This atypical reaction in schistosomes has recently been shown to be mediated by a novel family of anion-selective acetylcholine-gated channel subunits found in flatworms [26•]. Nematodes also express acetylcholine-activated channels that gate $\mathrm{Cl}^{-}$, although they appear to be more closely related to other types of $\mathrm{Cl}^{-}$channels than to nAChRs [32, 33].

nAchRs have proven to be especially fruitful targets for anthelmintics, particularly anti-nematodal drugs. Indeed, these receptors represent the most common targets of current anthelmintics (see Table 2). These include classic drugs such as the imidothiazoles (levamisole) and tetrahydropyrimidines (pyrantel, oxantel), which act as agonists [14•, 34], as well as more recently introduced compounds such as the aminoacetonitriles (monepantel) [35], tribendimidine [36•, 37], and the $\mathrm{nAchR}$ antagonist derquantel [36•]. As noted, nAchRs are pentameric structures, and the mixing and matching of the wide variety of available subunits provides the basis for a considerable diversity of receptors with distinct structural properties and pharmacological sensitivities. This potential for receptor diversity is particularly notable in nematodes, which typically contain genes encoding more $\mathrm{nAchR}$ subunits than do mammals [34, 38]. Striking variations in parasite nAchR pharmacology can be obtained by varying the subunits comprising the functional receptor $[14 \bullet$, 34, 38]. More remarkably, simply varying the stoichiometry of the same subunits can also dramatically alter receptor sensitivity to different anthelmintics [36•, 39]. Thus, parasites have the capacity to rapidly develop resistance against drugs that target these types of multi-subunit complexes simply by modifying expression patterns of existing subunits. On the other hand, this complexity in receptor composition suggests that development of resistance against one nAchR drug does not necessarily lead to cross-resistance against other drugs that act on variants of these receptors. This advantage has recently been illustrated by the development of monepantal, which targets a family of apparently nematode-specific neuronal nAchRs, and "breaks" resistance against other nAchR-targeting anthelmintics [35].

\section{Glutamate-Gated Chloride Channels}

Glutamate-gated chloride channels (GluCls) are another member of the Cys-loop ligand-gated channel family. Unlike the 
Table 2 Ion Channel Targets of Anthelmintics

\begin{tabular}{|c|c|c|}
\hline Anthelmintic Group & Examples & Target \\
\hline Imidazothiazoles & Levamisole & Nematodes; nAchR agonists $[14 \bullet, 34]$ \\
\hline Tetrahydropyrimidines & Pyrantel, oxantel, morantel & Nematodes; nAchR agonists $[14 \bullet, 34]$ \\
\hline Amino-acetonitriles & Monepantel & Nematodes; choline receptor agonists [35] \\
\hline Tribendimidine & & Nematodes; nAchR agonist $[36 \bullet, 37]$ \\
\hline Spiroindoles & Derquantel & Nematodes; nAchR antagonist [36•] \\
\hline Macrocyclic lactones & Ivermectin, moxidectin & Nematodes; $\mathrm{GluCl}$ activation $[28,42]$ \\
\hline Cyclo-octadepsipeptides & Emodepside & Nematodes; Slo-1 $\mathrm{K}^{+}$channels; latrophilin receptors $[75,76]$ \\
\hline Piperazine & & Nematodes; GABA receptor agonist [58] \\
\hline Pyrazino-isoquinoline & Praziquantel & Schistosomes, trematodes, cestodes; voltage-gated $\mathrm{Ca}^{2+}$ channels? $[15,16 \bullet]$ \\
\hline \multicolumn{3}{|c|}{ Other anthelmintics and targets: } \\
\hline Benzimidazoles & Albendazole, fenbendazole & Nematodes, trematodes; $\beta$-tubulin [95] \\
\hline Piperazine derivative & Diethylcarbamazine (DEC) & Filaricide; arachadonic acid pathways, anti-inflammatory, others? [96] \\
\hline Oxamniquine & & Schistosoma mansoni; DNA alkylation following activation by parasite sulfotransferase [97•] \\
\hline Artemisinins & Artesunate & Schistosomes; several candidate pathways [98] \\
\hline Antibiotics & Doxycycline & Wolbachia endosymbionts in filarial worms [99] \\
\hline
\end{tabular}

nAchRs, GluCls are confined to invertebrates, making them especially attractive anthelmintic (and insecticide) targets. As their name suggests, GluCls are gated by L-glutamate and permeable to $\mathrm{Cl}^{-}$. They underlie fast inhibitory transmission, hyperpolarizing the cell. The closest relatives of GluCls are mammalian glycine channels and $\mathrm{GABA}$-gated $\mathrm{Cl}^{-}$channels. GluCls play roles in locomotion, feeding, and sensory input, among other functions. Like other Cys-loop channels, GluCls are pentameric. Although channels containing a single subunit are functional [40], the subunit stoichiometry of the native channel is unknown. Recently, the X-ray structure of a Caenorhabditis elegans $\mathrm{GluCl}$ channel has been solved [41•], the first three-dimensional structure for a Cys-loop ligand-gated channel. Exhaustive reviews on the structure and properties of these channels have been published [42-44].

$\mathrm{GluCl}$ channels are targets for macrocyclic lactones, which include avermectin anthelmintics such as ivermectin and moxidectin, as well as the milbemycins. The macrocyclic lactones have proven extremely successful as anthelmintics (as well as insecticides and acaricides). They are used widely in human and veterinary medicine, most notably against filarial worms that cause diseases such as onchocerciasis (Onchocerca volvulus) and lymphatic filariasis (Wuchereria bancrofti) in humans, and heartworm disease (Dirofilaria caninum) in canines, paralyzing and killing the microfilariae and compromising fecundity of adults. In the case of Dirofilaria, slow killing and stunting of adults using longterm monthly prophylactic ivermectin therapy (soft kill) can be used as an alternative or adjunct to avoid the risks of rapid killing with the arsenical melarsomine [45].

The action of ivermectin on $\mathrm{GluCl}$ channels is slow but effectively irreversible, thereby rendering the channel essentially non-functional. Ivermectin can activate the channel itself, and it can also potentiate glutamate-gated activation [40]. Macrocyclic lactones act as allosteric regulators; ivermectin binds to a transmembrane site distinct from the Lglutamate-binding site, and appears to stabilize an open-pore conformation [41•]. Macrocyclic lactones also have activity against mammalian neuronal receptors, most notably the $\mathrm{GABA}_{\mathrm{A}}$-gated channel [46]. Ivermectin is also a positive allosteric modulator at vertebrate neuronal nAchRs [47], while abamectin, which is used commercially in combination with derquantel, has recently been shown to noncompetitively antagonize acetylcholine depolarizations and muscle contractions in Ascaris suum [48]. Ivermectin and other avermectins are also substrates for the multidrug transporter P-glycoprotein (Pgp) at the blood-brain barrier. Pgp mediates exclusion of these drugs from the mammalian central nervous system, thereby preventing interaction with CNS receptors; loss or disruption of host Pgp function can lead to ivermectin-induced neurological toxicity $[49,50]$.

Interestingly, the recently published genome of the hookworm Necator americanus [51] revealed that their $\mathrm{GluCl}$ channel genes appear to lack key residues for ivermectin activity, a finding which may explain the relatively low ivermectin sensitivity of these worms [52]. Schistosomes and other platyhelminths are typically not sensitive to macrocyclic lactones [53, 54] (though see [55]), which could suggest an absence of $\mathrm{GluCl}$ channels in these organisms. However, exciting recent work [56•] has demonstrated that schistosomes in fact do express $\mathrm{GluCl}$ channel subunits, but that these subunits are phylogenetically distinct from those of other invertebrates, including nematodes, arthropods, and molluscs. When expressed in Xenopus oocytes, schistosome $\mathrm{GluCl}$ subunits form functional L-glutamate-gated, $\mathrm{Cl}^{-}$-permeable channels. However, these expressed channels are unresponsive to 
$1 \mu \mathrm{M}$ ivermectin, thus distinguishing them from ivermectinsensitive $\mathrm{GluCl}$ channels. Since GluCls are already validated as drug targets in other parasites, these pharmacologically and phylogenetically distinct receptors may prove to be outstanding candidates for new or repurposed drugs targeting GluCls in schistosomes and other parasitic flatworms.

\section{GABA-Gated Chloride Channels}

GABA-gated chloride channels are ligand (GABA)-gated inhibitory channels that mediate the relaxation phase of nematode sinusoidal muscle movement [57]. GABA channel agonists such as the anthelmintic piperazine act on this channel to produce flaccid paralysis of the worm [58]. Macrocyclic lactones also appear to interact with nematode GABA-gated channels [57], and there is some evidence that the cyclooctadepsipeptide PF1022A (see below) binds to and interacts with nematode GABA receptors [59], although electrophysiological experiments suggest that it does not act as a GABA agonist [60]. Surprisingly, schistosomes do not appear to have genes for GABA-gated channels [56 $]$.

\section{Other Ligand-Gated Channels}

There are a host of other helminth ligand-gated ion channels with the potential to serve as attractive drug targets. These include a variety of inhibitory Cys-loop neurotransmitter (serotonin, dopamine, tyramine, AchR)-gated anion channels not found in mammals $[14 \cdot, 26 \bullet, 32]$. In addition to the $\mathrm{GluCl}$ channels, helminths also contain excitatory glutamate-gated cation channels, which play critical roles in the neuromusculature of animals. Interestingly, although schistosomes have functional $\left(\mathrm{Ca}^{2+}\right.$-permeable) P2X channels, nematodes apparently do not [61]. P2X channels act as receptors for extracellular ATP- and adenosine-mediated signaling, with roles in neurotransmission and intercellular signaling in a variety of tissues and organisms.

Many of these parasite ionotropic receptors still await detailed characterization, and may prove vulnerable to pharmacological disruption.

\section{Voltage-Gated Ion Channels}

Voltage-gated ion channels open in response to changes in membrane potential. They gate calcium $\left(\mathrm{Ca}_{\mathrm{v}}\right.$ channels), potassium $\left(\mathrm{K}_{\mathrm{v}}\right.$ channels), or sodium $\left(\mathrm{Na}_{\mathrm{v}}\right.$ channels), although some channels in this family are not highly ion selective, and instead permeate multiple cations; there are also voltage-gated proton channels [62], and voltage-gated chloride channels [63]. The voltage-gated ion channels underlie electrical signaling, including generation of action potentials. For example, $\mathrm{Na}_{\mathrm{v}}$ channels initiate $\mathrm{Na}^{+}$-based action potentials, and $\mathrm{K}_{\mathrm{v}}$ channels regulate resting membrane potential and repolarize the cell following excitatory events (e.g., action potentials). The $\mathrm{Ca}_{\mathrm{v}}$ channels have the additional special role of translating electrical signals into chemical signals [21], as they are a major conduit for the entry of $\mathrm{Ca}^{2+}$, a critical signaling molecule, into the cell. $\mathrm{Ca}_{\mathrm{v}}$ channels thus couple depolarization of the cell to a wide array of $\mathrm{Ca}^{2+}$-dependent responses.

There are several different sub-families within the different voltage-gated channel types. The $\mathrm{K}_{\mathrm{v}}$ channel family is hugely diverse, with almost $80 \mathrm{~K}_{\mathrm{v}}$ channel-encoding genes in mammals [64]. $\mathrm{K}_{\mathrm{v}}$ channels include the six-transmembrane voltage-gated $\mathrm{K}^{+}$channels; the six-transmembrane $\mathrm{Ca}^{2+}$-activated potassium channels; the two-transmembrane, inwardlyrectifying $\mathrm{K}_{\mathrm{ir}}$ channels; and the four-transmembrane, twopore channels (e.g., TWIK). The $\mathrm{Ca}_{\mathrm{v}}$ channel family consists of low voltage-activated $\left(\mathrm{Ca}_{\mathrm{v}} 3\right)$, and high voltage-activated $\left(\mathrm{Ca}_{\mathrm{v}} 1, \mathrm{Ca}_{\mathrm{v}} 2\right)$, families of pore-forming $\alpha 1$ subunits, with different subtypes within each family [65].

The architecture of these channels has been thoroughly studied [66]. Voltage-gated channels typically comprise four homologous transmembrane domains surrounding a central pore. Each domain typically contains six transmembrane regions, one of which acts as the voltage sensor. $\mathrm{K}_{\mathrm{v}}$ channel subunits contain a single domain, and a functional channel is a tetramer of four of these subunits (with the exception of 2pore, 4-transmembrane subunits, which form dimers). In contrast, $\mathrm{Na}_{\mathrm{v}}$ and $\mathrm{Ca}_{\mathrm{v}}$ channel subunits contain all four domains within the single protein chain; hence, these channels are monomeric. Auxiliary membrane and cytoplasmic subunits are associated with the pore-forming subunit and modulate its properties.

Both schistosomes and nematodes appear to lack $\mathrm{Na}_{\mathrm{v}}$ channels $[14 \cdot, 51,67$,$] . However, this lack of \mathrm{Na}_{\mathrm{v}}$ channels in the platyhelminths does not appear to be universal; a $\mathrm{Na}_{\mathrm{v}}$ channel-like cDNA has been reported in the turbellarian ectoparasitic flatworm Bdelloura candida [68], and a gene encoding a $\mathrm{Na}_{\mathrm{v}}$ channel-like subunit is present in the genome of the cestode Echinococcus granulosus [69, 70]. Whether these subunits form functional $\mathrm{Na}_{\mathrm{v}}$ channels remains to be determined, however.

In contrast to the situation with $\mathrm{Na}_{\mathrm{v}}$ channels, $\mathrm{K}_{\mathrm{v}}$ and $\mathrm{Ca}_{\mathrm{v}}$ channels are well represented in both nematode and flatworm genomes, with multiple classes and subtypes of each. Indeed, nematode genomes (C. elegans, $N$. americanus) code for approximately 50-80 different $\mathrm{K}_{\mathrm{v}}$ and $\mathrm{Ca}_{\mathrm{v}}$ channel genes $[51,71]$; the $S$. mansoni genome contains approximately 40 $\mathrm{K}_{\mathrm{v}}$ channel genes and four genes encoding high voltageactivated $\mathrm{Ca}_{\mathrm{v}}$ channel subunits [67]. Surprisingly, there appear to be no genes for low voltage-activated $\mathrm{Ca}_{\mathrm{v}}$ channel subunits in either the $S$. mansoni or $S$. japonicum genomes [72], suggesting either that schistosome excitable cells uniquely lack a 
requirement for the functions normally carried out by low voltage-activated $\mathrm{Ca}_{\mathrm{v}}$ channels, or that schistosomes recruit other channels to perform those functions (e.g., pacemaker activity).

Voltage-gated ion channels have served as particularly outstanding, although underexploited, drug targets [23, 73]. For example, $\mathrm{Ca}_{\mathrm{v}}$ channel blockers are used widely in cardiovascular medicine, and $\mathrm{Na}_{\mathrm{v}}$ channels are targets for local anesthetics. Insecticides such as DDT and pyrethroids act on arthropod $\mathrm{Na}_{\mathrm{v}}$ channels.

In contrast to these other systems, helminth voltage-gated (and related) ion channels are not well represented as drug targets, and further exploration is clearly warranted. Indeed, only two members of the voltage-gated ion channel superfamily have been implicated in the action of current anthelmintics: SLO-1 $\mathrm{Ca}^{2+}$-activated potassium channels for the antinematodal drug emodepside; and $\mathrm{Ca}_{\mathrm{v}}$ channels for the antischistosomal drug praziquantel.

\section{Nematode SLO-1 $\mathrm{Ca}^{2+}$-Activated Potassium Channels as Targets of Emodepside}

SLO-1 potassium channels are members of the BK (big $\mathrm{K}^{+}$ conductance) family of high-conductance $\mathrm{K}_{\mathrm{v}}$ channels [74]. SLO-1 channels can be activated by either depolarization alone, intracellular $\mathrm{Ca}^{2+}$ alone, or synergistically, by both. SLO-1 channels play important roles in the neuromuscular system, as well as in secretory cells, among others. Most relevant to this discussion, SLO-1 channels are required for the action of emodepside, a relatively recent anthelmintic currently used in veterinary medicine.

Emodepside is a semi-synthetic cyclo-octadepsipeptide anthelmintic derived from the fungus Roselliniaspp. PF1022 $[75,76]$. It has activity against a wide range of nematodes, and breaks resistance against other anthelmintics. Emodepside disrupts neuromuscular transmission, causing a flaccid paralysis; it also affects feeding and egg-laying, and slows development.

Several studies show that nematode SLO-1 channels are required for the action of emodepside. Loss-of-function mutations in the C. elegans SLO-1 channel-encoding slo-1 gene render the worms resistant to the effects of emodepside on both pharyngeal and locomotor activity. The slo-1 gain-offunction mutations phenocopy the effects of emodepside and slo-1 null mutants are rescued by transformation with wild type slo-1 [77]. Orthologues of slo- 1 from parasitic nematodes also restore emodepside sensitivity to the $C$. elegans loss-offunction mutants [78•]. In contrast, a human orthologue of slo1 does not confer emodepside sensitivity to these mutants, though it does rescue some of the behavioral deficiencies associated with the absence of the channel [79]. Electrophysiological studies on Ascaris suum are consistent with emodepside activation of SLO-1, but with a slow time course, possibly indicative of a non-extracellular binding site within the transmembrane domains [80].

Complicating the situation with emodepside is evidence showing that it interacts with other receptors as well, most notably the latrophilin receptor, a conserved G-proteincoupled receptor (GPCR) that binds the black widow spider toxin latrotoxin. A range of evidence $[60,76]$ implicates the latrophilin receptor in emodepside action in the pharynx, but not in body wall muscle. The current view appears to be that emodepside can act either directly or indirectly on SLO-1 channels. In the pharynx, emodepside apparently acts upstream of the SLO-1 channel, likely via the latrophilin receptor, to modulate SLO-1 activity, perhaps via phosphorylation; while the latrophilin receptor is not involved in emodepside activity on body wall musculature [78•].

\section{Flatworm $\mathrm{Ca}_{\mathrm{v}}$ Channels as Targets of Praziquantel}

Praziquantel is the current drug of choice against schistosomiasis [81, 82]. Indeed, it has become effectively the only drug available to treat a disease estimated to affect over 200 million people. Since its development in the 1970s, no new drugs (other than repurposed antimalarials such as artemisinins) have entered the market, and one drug used previously (oxamniquine) is essentially no longer available. Overall, praziquantel is quite effective, but a major shortcoming is that it is not active against immature, liver-stage schistosomes, a major concern in regions with high reinfection rates.

Furthermore, despite the availability of praziquantel for almost four decades, its molecular target is still not rigorously defined. However, substantial evidence implicates parasite $\mathrm{Ca}_{\mathrm{v}}$ channels in praziquantel action [15, 83, 84]. Early experiments on praziquantel showed that it produces a rapid influx of $\mathrm{Ca}^{2+}$ into the worm, and a $\mathrm{Ca}^{2+}$-dependent muscle contraction and paralysis. Several subsequent studies showed that an unusual $\mathrm{Ca}_{\mathrm{v}}$ channel auxiliary $\beta$ subunit, found only in platyhelminths, could confer praziquantel sensitivity to a mammalian $\mathrm{Ca}_{\mathrm{v}}$ channel subunit expressed in a heterologous system, and that this capacity could be eliminated by altering a single amino acid residue in the schistosome $\beta$ subunit [15].

Recent work that originated with studies on free-living planaria has substantiated the role of $\mathrm{Ca}_{\mathrm{v}}$ channels in praziquantel action $[16 \bullet, 85]$. Planarians have the extraordinary ability to regenerate a head and a tail when cut at both ends. However, praziquantel disrupts this capability, causing planaria instead to regenerate two heads instead of a head and a tail. Remarkably, suppression of $\mathrm{Ca}_{\mathrm{v}}$ channel subunit expression by RNA interference can override these effects of praziquantel, and the worms now show normal regenerative patterning in the presence of the drug. Recently, this 
praziquantel-dependent activation of a neuronal $\mathrm{Ca}_{\mathrm{v}}$ channel in planaria has been shown to regulate head structure formation by modulating dopaminergic and serotonergic pathways. Dopaminergic and serotonergic ligands that miscue regeneration also show antischistosomal activity, and compounds shown to have antischistosomal activity disrupt planarian regeneration [16•], suggesting conservation of initial signaling (e.g., activation of $\mathrm{Ca}_{\mathrm{v}}$ channels) with divergent downstream outputs.

\section{Related Targets}

TRP channels, a highly diverse set of cation channels that mediate transduction of sensory stimuli (light, sound, chemicals, temperature, and touch) and are well represented in both nematodes and schistosomes [86], are under intensive scrutiny as candidate targets for drugs to treat pain, cancer, and a host of other conditions [87]. Dysregulation of these channels might interfere with parasite signal transduction, and could also disrupt $\mathrm{Ca}^{2+}$ homeostasis in worms, as these channels are important in $\mathrm{Ca}^{2+}$ signaling cascades. Similarly, cyclic nucleotide gated channels, which are gated by intracellular cAMP or cGMP and are critical components of sensory transduction pathways, are present in these organisms and might serve as useful targets. A homolog of the recently-discovered mechanosensitive channel Piezo is present in C. elegans [88], and at least one gene encoding a Piezo-like protein is represented in the S. mansoni genome (Smp_136560). Intracellular ion channels such as ryanodine receptors and IP3 receptors regulate cytoplasmic $\mathrm{Ca}^{2+}$ levels, and might also serve as attractive targets.

Clearly, ion channels have proven to be extremely valuable as targets for anthelmintics, but other components of parasite neuronal signaling might also serve as fertile ground for new therapeutics. For example, neurotransmitter transporters, which translocate neurotransmitters across membranes, are critical for regulating neurotransmission, are validated drug targets in human medicine, and are critical to normal neuronal functioning in helminths [89]. GPCRs play essential roles in signal transduction, and are estimated to be molecular targets for more than $30 \%$ of current drugs [90]. GPCRs also vary widely in their ligand specificity, providing the opportunity for parasite-selective activity. As noted above, the latrophilin GPCR appears to play an important role in the action of emodepside. Furthermore, neurotransmitters that activate ionotropic receptors often also act on separate classes of GPCRs (e.g., nAchRs vs. muscarinic AchRs). Downstream signaling cascades may also be targeted, as can enzymes involved in synthesis or degradation of neurotransmitters. As noted by others [14•], helminths and other invertebrates signal via neuropeptides and peptide receptors that are critical to neuromuscular function, but that are not found in vertebrates, and thus could serve as potential drug targets.

\section{ABC Transporters}

ATP binding cassette $(\mathrm{ABC})$ multidrug transporters are members of the $\mathrm{ABC}$ protein superfamily, a large and ancient group of proteins. They are ATP-dependent efflux transporters with broad substrate specificity. P-glycoprotein (Pgp; ABCB1), multidrug resistance associated proteins (MRPs; $A B C C s$ ), and breast cancer resistance protein (BCRP; ABCG2), are implicated in multidrug resistance in mammalian cells. As mentioned above, ivermectin is a substrate for mammalian Pgp at the blood-brain barrier, and it is also a substrate for nematode Pgp. Although they are neither ion channels nor critical components of neuromuscular signaling, evidence is accruing [91-93] that by modulating effective intra-worm concentrations of compounds, parasite $\mathrm{ABC}$ transporters can regulate levels of anthelmintic efficacy. They also appear to play a role in the development or maintenance of anthelmintic resistance, and several studies indicate that inhibiting these transporters can overcome resistance. We and others have postulated that the roles helminth $\mathrm{ABC}$ transporters play in modulating drug susceptibility might be exploitable in a strategy that combines new or repurposed transporter inhibitors with current anthelmintics to enhance drug susceptibility. Notably, there are many safe, inexpensive drugs available that, in addition to targeting their primary receptors, interact with these drug transporters, and might be suitable for short-term combination therapy. Furthermore, it is likely that helminth $\mathrm{ABC}$ transporters play key roles in critical worm physiological functions such as excretion, reproduction, and perhaps modulation of host responses. As such, they may prove to be attractive therapeutic targets on their own.

\section{Conclusions}

There are at least two related motivations for defining targets of current anthelmintics and identifying candidate targets for new therapeutics. The most obvious is the inadequate number of currently available drugs in the face of an estimated one billion people or more infected with helminth parasites [1]. Add to these numbers the vast economic damage due to helminth infections of farm animals and agricultural crops, and the need for new anthelmintics becomes even more urgent. The second, related factor in this calculus is drug resistance. Drug resistance has emerged against essentially every class of anthelmintic used in veterinary medicine, often within as few as 3-4 years following introduction [94]. Although the problem is, as far as we know, not as dire in human medicine, and most anthelmintics appear to continue to show 
effectiveness, there have been reports of insusceptibility in the field and resistance can be experimentally induced [82]. The increased implementation of mass drug administration programs may serve to accelerate the emergence of resistance, adding further urgency to the need for new therapeutics. Most helminth ion channels remain to be characterized. Doing so will provide important information about the physiology of these organisms and the evolution of ion channels and neuromuscular systems, and may ultimately provide new candidate targets for development of novel anthelmintics.

Acknowledgments Research in the laboratory on ion channels and drug transporters in schistosomes is supported by NIH grants R21AI112713, R21AI106268, and R21AI100505, and by a Bill \& Melinda Gates Foundation Grand Challenges Explorations award.

\section{Compliance with Ethics Guidelines}

Conflict of Interest Dr. Greenberg reports grants from National Institutes of Health, and grants from Bill and Melinda Gates Foundation, during the study.

Human and Animal Rights and Informed Consent This article does not contain any studies with human or animal subjects performed by any of the authors.

\section{References}

Papers of particular interest, published recently, have been highlighted as

- Of importance

1. Hotez PJ, Brindley PJ, Bethony JM, King CH, Pearce EJ, Jacobson J. Helminth infections: the great neglected tropical diseases. J Clin Investig. 2008;118:1311-21. doi:10.1172/JCI34261.

2. Lustigman S, Prichard RK, Gazzinelli A, Grant WN, Boatin BA, McCarthy JS, et al. A research agenda for helminth diseases of humans: the problem of helminthiases. PLoS Negl Trop Dis. 2012;6:e1582. doi:10.1371/journal.pntd.0001582.

3. Hotez PJ, Molyneux DH, Fenwick A, Kumaresan J, Sachs SE, Sachs JD, et al. Control of neglected tropical diseases. New Engl J Med. 2007;357:1018-27.

4. Fenwick A. The global burden of neglected tropical diseases. Public Health. 2012;126:233-6. doi:10.1016/j.puhe.2011.11.015.

5. Charlier J, van der Voort M, Kenyon F, Skuce P, Vercruysse J. Chasing helminths and their economic impact on farmed ruminants. Trends Parasitol. 2014;30:361-7. doi:10.1016/j.pt.2014.04.009.

6. Bird DM, Kaloshian I. Are roots special? Nematodes have their say. Physiol Mol Plant Pathol. 2003;62:115-23.

7. Tanaka H, Tsuji M. From discovery to eradication of schistosomiasis in Japan: 1847-1996. Int J Parasitol. 1997;27:1465-80.

8. Bethony JM, Cole RN, Guo X, Kamhawi S, Lightowlers MW, Loukas A, et al. Vaccines to combat the neglected tropical diseases. Immunol Rev. 2011;239(1):237-70. doi:10.1111/j.1600-065X. 2010.00976.x.

9. Beaumier CM, Gillespie PM, Hotez PJ, Bottazzi ME. New vaccines for neglected parasitic diseases and dengue. Transl Res. 2013;162(3):144-55. doi:10.1016/j.trsl.2013.03.006.
10. Prichard RK, Basanez MG, Boatin BA, McCarthy JS, Garcia HH, Yang GJ, et al. A research agenda for helminth diseases of humans: intervention for control and elimination. PLoS Negl Trop Dis. 2012;6:e1549. doi:10.1371/journal.pntd.0001549.

11. Ribeiro P, Geary TG. Neuronal signaling in schistosomes: current status and prospects for postgenomics. Can J Zool. 2010;88:1-22. doi:10.1139/Z09-126.

12. Perry RN, Maule AG. Physiological and biochemical basis of behaviour. In: Gaugler R, Bigrami AL, editors. Nematode Behaviour. Oxfordshire: CABI Publishing; 2004. p. 197-238.

13. White JG, Southgate E, Thomson JN, Brenner S. The structure of the nervous system of the nematode Caenorhabditis elegans. Philos Trans R Soc B. 1986;314:1-340. doi:10.1098/rstb.1986.0056.

14. Wolstenholme A. Ion channels and receptor as targets for the control of parasitic nematodes. Int J Parasitology: Drugs and Drug Resist. 2011;1:2-13. Comprehensive review of nematode ion channels and receptors as drug targets.

15. Greenberg RM. Are $\mathrm{Ca}^{2+}$ channels targets of praziquantel action? Int J Parasitol. 2005;35(1):1-9.

16. Chan JD, Agbedanu PN, Zamamian M, Gruba SM, Haynes CL, Day TA, et al. 'Death and axes': unexpected $\mathrm{Ca}^{2+}$ entry phenologs predict new anti-schistosomal agents. Plos Pathog. 2014;10: e1003942. doi:10.1371/journal.ppat.1003942. Translates mechanisms of praziquantel action in disrupting planarian regeneration into schistosomes, and provides a model linking the two systems.

17. Anderson PA, Greenberg RM. Phylogeny of ion channels: clues to structure and function. Comp Biochem Physiol B: Biochem Mol Biol. 2001;129(1):17-28.

18. Jeziorski MC, Greenberg RM, Anderson PA. The molecular biology of invertebrate voltage-gated $\mathrm{Ca}^{2+}$ channels. J Exp Biol. 2000;203(Pt 5):841-56.

19. Cai X. Evolutionary genomics reveals the premetazoan origin of opposite gating polarity in animal-type voltage-gated ion channels. Genomics. 2012;99:241-5. doi:10.1016/j.ygeno.2012.01.007.

20. Kwa MSG, Veenstra JG, Dijk MV. Roos MH $\beta$-tubulin genes from the parasitic nematode Haemonchus contortus modulate drug resistance in Caenorhabditis elegans. J Mol Biol. 1995;246:500-10.

21. Hille B. Ion channels of excitable membranes. 3rd ed. Sunderland: Sinauer Associates; 2001.

22. Kullmann DM, Waxman SG. Neurological channelopathies: new insights into disease mechanisms and ion channel function. $\mathrm{J}$ Physiol. 2010;588:1823-7. doi:10.1113/jphysiol.2010.190652.

23. Camerino DC, Tricarico D, Desaphy JF. Ion channel pharmacology. Neurotherapeutics. 2007;4:184-98.

24. Millar NS, Harkness PC. Assembly and trafficking of nicotinic acetylcholine receptors. Mol Membr Biol. 2008;25:279-92. doi: 10.1080/09687680802035675.

25. van Nierop $P$, Keramidas A, Bertrand S, van Minnen J, Gouwenberg Y, Bertrand D, et al. Identification of molluscan nicotinic acetylcholine receptor ( $\mathrm{nAChR}$ ) subunits involved in formation of cation- and anion-selective nAChRs. J Neurosci. 2005;25:10617-26.

26. MacDonald K, Buxton S, Kimber MJ, Day TA, Robertson AP, Ribeiro P. Functional characterization of a novel family of acetylcholine-gated chloride channels in Schistosoma mansoni. Plos Pathog. 2014;10:e1004181. doi:10.1371/journal.ppat. 1004181. Discovery of a novel class of schistosome anionselective $n$ AchRs.

27. Rand JB. Acetylcholine. In: The C. elegans Research Community, editor. WormBook. http://www.wormbook.org; Jan. 30, 2007. p. 1-21.

28. Robertson AP, Martin RJ. Ion-channels on parasite muscle: pharmacology and physiology. Invertebr Neurosci. 2007;7(4):209-17. doi:10.1007/s10158-007-0059-x.

29. Maule AG, Marks NJ, Day TA. Signalling molecules and nervemuscle function. In: Maule AG, Marks NJ, editors. Parasitic 
Flatworms: Molecular Biology, Biochemistry, Immunology, and Physiology. Oxfordshire: CAB International; 2006. p. 369-86.

30. Day TA, Chen GZ, Miller C, Tian M. Cholinergic inhibition of muscle fibres isolated from Schistosoma mansoni (Trematoda: Digenea). Parasitology. 1996;113:55-61.

31. Ribeiro P, El-Shehabi F, Patocka N. Classical transmitters and their receptors in flatworms. Parasitology. 2005;131:S19-40.

32. Beech RN, Callanan MK, Rao VT, Dawe GB, Forrester SG. Characterization of cys-loop receptor genes involved in inhibitory amine neurotransmission in parasitic and free living nematodes. Parasitol Int. 2013;62:599-605. doi:10.1016/j.parint.2013.03.010.

33. Putrenko I, Zakikhani M, Dent JA. A family of acetylcholine-gated chloride channel subunits in Caenorhabditis elegans. J Biol Chem. 2005;280:6392-8.

34. Holden-Dye L, Joyner M, O'Connor V, Walker RJ. Nicotinic acetylcholine receptors: A comparison of the nAChRs of Caenorhabditis elegans and parasitic nematodes. Parasitol Int. 2013;62:606-15. doi:10.1016/j.parint.2013.03.004.

35. Kaminsky R, Ducray P, Jung M, Clover R, Rufener L, Bouvier J, et al. A new class of anthelmintics effective against drug-resistant nematodes. Nature. 2008;452:176-80. doi:10.1038/nature06722.

36. Buxton SK, Charvet CL, Neveu C, Cabaret J, Cortet J, Peineau N, et al. Investigation of acetylcholine receptor diversity in a nematode parasite leads to characterization of tribendimidine- and derquantelsensitive nAChRs. Plos Pathog. 2014;10:e1003870. doi:10.1371/ journal.ppat.1003870. Defines $n$ AchR subunits underlying action of newer $n$ AchR-targeted anthelmintics in a parasitic nematode.

37. $\mathrm{Hu} \mathrm{Y,} \mathrm{Xiao} \mathrm{SH,} \mathrm{Aroian} \mathrm{RV.} \mathrm{The} \mathrm{new} \mathrm{anthelmintic} \mathrm{tribendimidine} \mathrm{is}$ an L-type (levamisole and pyrantel) nicotinic acetylcholine receptor agonist. PLoS Negl Trop Dis. 2009;3:e499. doi:10.1371/journal. pntd.0000499.

38. Sattelle DB. Invertebrate nicotinic acetylcholine receptors-targets for chemicals and drugs important in agriculture, veterinary medicine and human health. J Pestic Sci. 2009;34:233-40. doi:10.1584/ jpestics.R09-02.

39. Williamson SM, Robertson AP, Brown L, Williams T, Woods DJ, Martin RJ, et al. The nicotinic acetylcholine receptors of the parasitic nematode Ascaris suum: formation of two distinct drug targets by varying the relative expression levels of two subunits. Plos Pathog. 2009;5:e1000517.

40. Cully DF, Vassilatis DK, Liu KK, Paress PS, Van der Ploeg LH, Schaeffer JM, et al. Cloning of an avermectin-sensitive glutamategated chloride channel from Caenorhabditis elegans. Nature. 1994;371:707-11.

41. Hibbs RE, Gouaux E. Principles of activation and permeation in an anion-selective Cys-loop receptor. Nature. 2011;474:54-60. doi:10. 1038/nature10139. Structure of the C. elegans GluCl channel, the first cys-loop channel structure solved.

42. Wolstenholme A. Glutamate-gated chloride channels. J Biol Chem. 2012;287:40232-8. doi:10.1074/jbc.R112.406280.

43. Cleland TA. Inhibitory glutamate receptor channels. Mol Neurobiol. 1996;13:97-136.

44. Wolstenholme AJ, Rogers AT. Glutamate-gated chloride channels and the mode of action of the avermectin/milbemycin anthelmintics. Parasitology. 2005;131:S85-95.

45. Nolan TJ, Lok JB. Macrocyclic lactones in the treatment and control of parasitism in small companion animals. Curr Pharm Biotechnol. 2012;13:1078-94.

46. Menez C, Sutra JF, Prichard R, Lespine A. Relative neurotoxicity of ivermectin and moxidectin in Mdrlab (-/-) mice and effects on mammalian GABA(A) channel activity. PLoS Negl Trop Dis. 2012;6:e1883. doi:10.1371/journal.pntd.0001883.

47. Krause RM, Buisson B, Bertrand S, Corringer PJ, Galzi JL, Changeux JP, et al. Ivermectin: a positive allosteric effector of the $\alpha 7$ neuronal nicotinic acetylcholine receptor. Mol Pharmacol. 1998;53:283-94.
48. Puttachary S, Trailovic SM, Robertson AP, Thompson DP, Woods DJ, Martin RJ. Derquantel and abamectin: effects and interactions on isolated tissues of Ascaris suum. Mol Biochem Parasitol. 2013;188:79-86. doi:10.1016/j.molbiopara.2013.02.004.

49. Mealey KL, Bentjen SA, Gay JM, Cantor GH. Ivermectin sensitivity in collies is associated with a deletion mutation of the mdrl gene. Pharmacogenetics. 2001;11:727-33.

50. Schinkel AH, Smit JJ, van Tellingen O, Beijnen JH, Wagenaar E, van Deemter L, et al. Disruption of the mouse mdrla P-glycoprotein gene leads to a deficiency in the blood-brain barrier and to increased sensitivity to drugs. Cell. 1994;77:491-502.

51. Tang YT, Gao X, Rosa BA, Abubucker S, Hallsworth-Pepin K, Martin J, et al. Genome of the human hookworm Necator americanus. Nat Genet. 2014;46(3):261-9. doi:10.1038/ng.2875.

52. Richards JC, Behnke JM, Duce IR. In vitro studies on the relative sensitivity to ivermectin of Necator americanus and Ancylostoma ceylanicum. Int J Parasitol. 1995;25:1185-91.

53. Campbell WC, Fisher MH, Stapley EO, Albers-Schonberg G, Jacob TA. Ivermectin: a potent new antiparasitic agent. Science. 1983;221:823-8.

54. Shoop WL, Ostlind DA, Rohrer SP, Mickle G, Haines HW, Michael BF, et al. Avermectins and milbemycins against Fasciola hepatica: in vivo drug efficacy and in vitro receptor binding. Int $\mathrm{J}$ Parasitol. 1995;25:923-7.

55. Taman A, El-Beshbishi S, El-Tantawy N, El-Hawary A, Azab M. Evaluation of the in vivo effect of ivermectin on Schistosoma mansoni in experimentally-infected mice. J Coast Life Med. 2014;2:817-23. doi:10.12980/JCLM.2.201414D107.

56. Dufour V, Beech RN, Wever C, Dent JA, Geary TG. Molecular cloning and characterization of novel glutamate-gated chloride channel subunits from Schistosoma mansoni. Plos Pathog. 2013;9: e1003586. doi:10.1371/journal.ppat.1003586. Discovery of a novel class of ivermectin-insensitive $\mathrm{GluCl}$ channels in schistosomes and other platyhelminths.

57. Accardi MV, Beech RN, Forrester SG. Nematode cys-loop GABA receptors: biological function, pharmacology and sites of action for anthelmintics. Invertebr Neurosci. 2013;12:3-12. doi:10.1007/ s10158-012-0129-6.

58. Martin RJ. $\gamma$-Aminobutyric acid- and piperazine-activated singlechannel currents from Ascaris suum body muscle. Br J Pharmacol. 1985;84:445-61.

59. Harder A, Schmitt-Wrede HP, Krucken J, Marinovski P, Wunderlich F, Wilson J, et al. Cyclooctadepsipeptides-an anthelmintically active class of compounds exhibiting a novel mode of action. Int J Antimicrob Agents. 2003;22:318-31.

60. Martin RJ, Buxton SK, Neveu C, Charvet CL, Robertson AP. Emodepside and SLO-1 potassium channels: a review. Exp Parasitol. 2012;132:40-6. doi:10.1016/j.exppara.2011.08.012.

61. Burnstock G, Verkhratsky A. Evolution of P2X receptors. WIREs Membrane Transport and Signaling. 2012;1:188-200. doi:10.1002/ wmts.13.

62. DeCoursey TE. Voltage-gated proton channels: molecular biology, physiology, and pathophysiology of the $\mathrm{H}_{\mathrm{V}}$ family. Physiol Rev. 2013;93:599-652. doi:10.1152/physrev.00011.2012.

63. Duran C, Thompson CH, Xiao Q, Hartzell HC. Chloride channels: often enigmatic, rarely predictable. Annu Rev Physiol. 2010;72:95121. doi:10.1146/annurev-physiol-021909-135811.

64. Pardo LA, Stuhmer W. The roles of $\mathrm{K}^{+}$channels in cancer. Nat Rev Cancer. 2014;14:39-48. doi:10.1038/nrc3635.

65. Simms BA, Zamponi GW. Neuronal voltage-gated calcium channels: structure, function, and dysfunction. Neuron. 2014;82:24-45. doi:10.1016/j.neuron.2014.03.016.

66. Yu FH, Yarov-Yarovoy V, Gutman GA, Catterall WA. Overview of molecular relationships in the voltage-gated ion channel superfamily. Pharmacol Rev. 2005;57(4):387-95. 
67. Berriman M, Haas BJ, LoVerde PT, Wilson RA, Dillon GP, Cerqueira GC, et al. The genome of the blood fluke Schistosoma mansoni. Nature. 2009;460(7253):352-8. doi:10.1038/ nature 08160

68. Jeziorski MC, Greenberg RM, Anderson PA. Cloning of a putative voltage-gated sodium channel from the turbellarian flatworm Bdelloura candida. Parasitology. 1997;115(Pt 3):289-96.

69. Tsai IJ, Zarowiecki M, Holroyd N, Garciarrubio A, Sanchez-Flores A, Brooks KL, et al. The genomes of four tapeworm species reveal adaptations to parasitism. Nature. 2013;496(7443):57-63. doi:10. 1038/nature12031.

70. Zheng H, Zhang W, Zhang L, Zhang Z, Li J, Lu G, et al. The genome of the hydatid tapeworm Echinococcus granulosus. Nat Genet. 2013;45(10):1168-75. doi:10.1038/ng.2757.

71. Bargmann CI. Neurobiology of the Caenorhabditis elegans genome. Science. 1998;282:2028-33

72. Salvador-Recatala V, Greenberg RM. Calcium channels of schistosomes: unresolved questions and unexpected answers. WIREs Membrane Transport and Signaling. 2011;in press.

73. Davies TG, Field LM, Usherwood PN, Williamson MS. DDT, pyrethrins, pyrethroids and insect sodium channels. IUBMB Life. 2007;59:151-62.

74. Salkoff L, Butler A, Ferreira G, Santi C, Wei A. High-conductance potassium channels of the SLO family. Nat Rev Neurosci. 2006;7: 921-31.

75. Krucken J, Harder A, Jeschke P, Holden-Dye L, O'Connor V, Welz $\mathrm{C}$, et al. Anthelmintic cyclcooctadepsipeptides: complex in structure and mode of action. Trends Parasitol. 2012;28:385-94. doi:10. 1016/j.pt.2012.06.005.

76. Holden-Dye L, Crisford A, Welz C, von Samson-Himmelstjerna G, Walker RJ, O'Connor V. Worms take to the slo lane: a perspective on the mode of action of emodepside. Invertebr Neurosci. 2012;12: 29-36. doi:10.1007/s10158-012-0133-x.

77. Guest M, Bull K, Walker RJ, Amliwala K, O'Connor V, Harder A, et al. The calcium-activated potassium channel, SLO-1, is required for the action of the novel cyclo-octadepsipeptide anthelmintic, emodepside, in Caenorhabditis elegans. Int J Parasitol. 2007;37: 1577-88.

78. Welz C, Kruger N, Schniederjans M, Miltsch SM, Krucken J, Guest $\mathrm{M}$, et al. SLO-1-channels of parasitic nematodes reconstitute locomotor behaviour and emodepside sensitivity in Caenorhabditis elegans slo-1 loss of function mutants. Plos Pathog. 2011;7: e1001330. doi:10.1371/journal.ppat.1001330. Shows that SLO-1 from parasitic nematodes can rescue emodepside sensitivity in $C$. elegans loss of function mutants.

79. Crisford A, Murray C, O'Connor V, Edwards RJ, Kruger N, Welz C, et al. Selective toxicity of the anthelmintic emodepside revealed by heterologous expression of human KCNMA1 in Caenorhabditis elegans. Mol Pharmacol. 2011;79:1031-43. doi:10.1124/mol.111. 071043.

80. Buxton SK, Neveu C, Charvet CL, Robertson AP, Martin RJ. On the mode of action of emodepside: slow effects on membrane potential and voltage-activated currents in Ascaris suum. Br J Pharmacol. 2011;164:453-70. doi:10.1111/j.1476-5381.2011. 01428.x.

81. Cioli D, Pica Mattoccia L, Basso A, Guidi A. Schistosomiasis control: praziquantel forever? Molecular and Biochemical Parasitology. 2014;195:23-9. doi:10.1016/j.molbiopara.2014.06.002.
82. Greenberg RM. New approaches for understanding mechanisms of drug resistance in schistosomes. Parasitology. 2013;140:1534-46. doi:10.1017/S0031182013000231.

83. Doenhoff MJ, Cioli D, Utzinger J. Praziquantel: mechanisms of action, resistance and new derivatives for schistosomiasis. Curr Opin Infect Dis. 2008;21(6):659-67. doi:10.1097/QCO. 0b013e328318978f.

84. Redman CA, Robertson A, Fallon PG, Modha J, Kusel JR, Doenhoff MJ, et al. Praziquantel: an urgent and exciting challenge. Parasitol Today. 1996;12(1):14-20.

85. Chan JD, Zarowiecki M, Marchant JS. $\mathrm{Ca}^{2+}$ channels and praziquantel: a view from the free world. Parasitol Int. 2013;62(6):619-28. doi:10.1016/j.parint.2012.12.001.

86. Wolstenholme AJ, Williamson SM, Reaves BJ. TRP channels in parasites. Adv Exp Med Biol. 2011;704:358-71.

87. Kaneko Y, Szallasi A. Transient receptor potential (TRP) channels: a clinical perspective. Br J Pharmacol. 2014;171:2474-507. doi:10. 1111/bph.12414.

88. Coste B, Mathur J, Schmidt M, Earley TJ, Ranade S, Petrus MJ, et al. Piezo1 and Piezo2 are essential components of distinct mechanically activated cation channels. Science. 2010;330:55-60. doi: 10.1126/science.1193270.

89. Ribeiro P, Patocka N. Neurotransmitter transporters in schistosomes: structure, function and prospects for drug discovery. Parasitol Int. 2013;62:629-38. doi:10.1016/j.parint.2013.06.003.

90. Wise A, Gearing K, Rees S. Target validation of G-protein coupled receptors. Drug Discov Today. 2002;7:235-46.

91. Ardelli BF. Transport proteins of the ABC systems superfamily and their role in drug action and resistance in nematodes. Parasitol Int. 2013;62:639-46. doi:10.1016/j.parint.2013.02.008.

92. Greenberg RM. ABC multidrug transporters in schistosomes and other parasitic flatworms. Parasitol Int. 2013;62:647-53. doi:10. 1016/j.parint.2013.02.006.

93. Lespine A, Menez C, Bourguinat C, Prichard RK. P-glycoproteins and other multidrug resistance transporters in the pharmacology of anthelmintics: prospects for reversing transport-dependent anthelmintic resistance. International Journal for Parasitology: Drugs and Drug Resistance. 2012;2:58-75. doi:10.1016/j.ijpddr.2011.10.001.

94. James CE, Hudson AL, Davey MW. Drug resistance mechanisms in helminths: is it survival of the fittest? Trends Parasitol. 2009;25(7):328-35. doi:10.1016/j.pt.2009.04.004.

95. Kohler P. The biochemical basis of anthelmintic action and resistance. Int J Parasitol. 2001;31:336-45.

96. Peixoto CA, Silva BS. Anti-inflammatory effects of diethylcarbamazine: A review. Eur J Pharmacol. 2014;734:35-41. doi:10.1016/j. ejphar.2014.03.046.

97. Valentim CL, Cioli D, Chevalier FD, Cao X, Taylor AB, Holloway SP, et al. Genetic and molecular basis of drug resistance and speciesspecific drug action in schistosome parasites. Science. 2013;342: 1385-9. doi:10.1126/science.1243106. Not about an ion channel drug, but the first full description of the mechanism of action of an anthelmintic drug, from gene to structure.

98. Ho WE, Peh HY, Chan TK, Wong WS. Artemisinins: pharmacological actions beyond anti-malarial. Pharmacol Ther. 2014;142: 126-39. doi:10.1016/j.pharmthera.2013.12.001.

99. Slatko BE, Luck AN, Dobson SL, Forster JM. Wolbachia endosymbionts and human disease control. Molecular and Biochemical Parasitology. 2014;195:88-95. doi:10.1016/j.molbiopara.2014.07.004. 